\title{
Limited Epistocracy and Political Inclusion
}

\author{
Anne Jeffrey \\ (penultimate draft; forthcoming in Episteme)
}

In this paper I defend a form of epistocracy I call limited epistocracy - rule by institutions housing expertise in non-political areas that become politically relevant. This kind of limited epistocracy, I argue, isn't a far-off fiction. With increasing frequency, governments are outsourcing political power to expert institutions to solve urgent, multidimensional problems because they outperform ordinary democratic decision-making. I consider the objection that limited epistocracy, while more effective than its competitors, lacks a fundamental intrinsic value that its competitors have; namely, political inclusion. After explaining this challenge, I suggest that limited epistocracies can be made compatible with robust political inclusion if specialized institutions are confined to issuing directives that give citizens multiple actionable options. I explain how this safeguards citizens' inclusion through rational deliberation, choice, and contestation.

\section{Introduction}

Recently, many governments have been addressing urgent, multidimensional problems like climate change, the Ebola and Zika outbreaks, and the Syrian refugee crisis by turning over the reins to expert institutions. Groups like the World Health Organization (WHO), the Intergovernmental Panel on Climate Change (IPCC), and the Migration Policy Institute (MPI) can provide better solutions to these problems than individual experts because, as William Rehg aptly puts it, "the multidisciplinary complexity of the technical issues exceeds the technical expertise of any one person," (2011, p. 386). When such issues arise, our best hope of resolving 
them effectively lies in deferring to institutions with specialized knowledge.

In this paper I defend the form of government best equipped to resolve these kinds of complex problems: limited epistocracy. Limited epistocracy, as I'll define it, is qualified rule by expert institutions, where the institutions get their political authority in virtue of their specialized knowledge and their ability to generate optimal solutions in the way of, for instance, health, environmental sustainability, technological security, and border regulation. My main aim is to show that limited epistocracy is a viable and preferable alternative to democracy because of its ability to produce better outcomes while also realizing the value of political inclusion (a value typically associated with democratic regimes).

After defining limited epistocracy, I explain why we should think of it as a serious and attractive form of rule distinct from democracy. Then I consider what I take to be the most formidable objections to limited epistocracy that might be leveled by democrats. First, democrats might object that limited epistocracy won't be legitimate because it doesn't satisfy a liberal principle that democracy does. Second, democrats could object that limited epistocracy could result in certain groups being unfairly excluded from political participation. I respond to each of these objections in turn.

If the defense is successful, at best it will show that limited epistocracy can do better than democracy and protect a central democratic value - political inclusion. At worst, if democrats still want to argue that democracy can take on board much of what I suggest without collapsing into limited epistocracy, then my argument will reveal that democrats are willing to concede much more in the way of the intrinsic values that make democracy distinctive - like protection of individual liberties and political participation - than we might expect.

\section{Specialized Institutions As Epistocrats}


There are doubtless many kinds of epistocracy we might aptly describe as "limited epistocracy." 1 The variety of limited epistocracy I want to defend is rule by a certain kind of organized body of experts, which I'll call a specialized institution, with the political power to make decisions and issue commands in the area of their expertise. A specialized institution's rule is limited in the sense that the domain in which it's authorized is circumscribed by its expertise. If organizations like the WHO, IPCC, and WTO ever function as specialized institutions in my sense (and I'm going to suggest that on occasion, they have), it is usually ad hoc and temporary or over a narrow domain, where they are authorized to resolve some particularly pressing issue facing the nation(s) that empower them.

This variety of limited epistocracy is of interest for a few reasons. It avoids seemingly intractable disagreements about what suffices for political expertise because the expertise of specialized institutions is not primarily political. Instead, it's expertise in subjects like medicine, public health, or climate science, that neither the average citizen nor elected political officials can be expected to have. The epistemic communities in those areas already have standards by which they judge who qualifies as an expert. Critics of wholesale epistocracy are quick to point out that fairly settling the question of who counts as a political expert would be a formidable task. For one thing, as the literature on moral disagreement and moral expertise shows us, rampant disagreement on evaluative matters can easily lead to skepticism about moral knowledge and expertise altogether. For another, if there are moral or political experts, we can't check their expertise by seeing if their predictions and products hold up without already adopting a certain moral or political standard for evaluation, which could be wrong. But that won't be a problem for this kind of limited epistocracy. There is not widespread disagreement among non-experts as to who has expertise in social or hard sciences; the experts are generally regarded as

\footnotetext{
${ }^{1}$ Jason Brennan, for instance, proposes a variety in which a state grants universal suffrage with epistocratic veto. Since the epistocrats' power is limited to striking down, rather than creating, laws, we could call this a limited epistocracy (2016, pp. 215-218). Thomas Christiano describes a system in which all citizens can make determinations about the aims of their society, but experts decide on the means to achieving those aims (2006).
} 
experts because we trust their credentials. The epistemic communities in the areas of these institutions' specialization have established standards for judging expertise which non-experts rely on in evaluating others as experts. Those standards being external to politics, we don't need to worry that political biases will pollute the process of designating individuals and institutions as experts.

Additionally, this kind of limited epistocracy incorporates an insight of Aristotle's offered by democrats as a reason to resist full epistocracy. The insight is that rule by a group of fairly wise individuals could outperform rule by the wisest individual, since deliberation with the group could produce better results than unchecked judgments of an individual even when the average competence is slightly lower in the group. ${ }^{2}$ Helene Landemore puts the objection this way: "Epistocracy is not a tempting option...not because we can never agree on who the knowers are, or because there are no knowers whose expertise is beyond other citizens' reasonable objections... but because the more reliable knower is actually the group as a whole, as opposed to any particular individual or group of individuals within it," (2012, p. 10). Since specialized institutions incorporate a large number of experts of varying, but still high, levels of competence, their outputs will likely be superior to those that an individual - say, a singular genius in the field - would generate.

In a specialized institution, the experts are equipped to decide and act quickly in emergencies. Unlike a group of people who happen to be experts in some area but have no experience collaborating with each other, a specialized institution has established procedures for joint problem solving. ${ }^{3}$ They would handily outperform a purely democratic regime or even a regime where democratically elected officials were advised by experts but held ultimate decision-making power. So, if any form of epistocracy stands a chance of appealing even to those democrats who have raised epistemic worries about epistocracy, limited epistocracy does.

\footnotetext{
${ }^{2}$ For thorough discussion of this criticism see Estlund (2008, pp. 208-209).

${ }^{3}$ Henry Richardson points out four reasons why specialized institutions with expertise are indispensible to collaborative reasoning: they "catalyze a moment of joint decision," they authorize "certain individuals...to play certain roles," they "constitute the group as a reasoner," and the "distinctive institutional structure will help a collective agent achieve this kind of decisional autonomy," (2012, pp. 100-101).
} 
Let's consider the features a specialized institution qualified for this kind of epistocratic governance would need to have. For one thing, it will have a unique relationship to a body of information. The knowledge housed in a specialized institution is not common: it's neither acquirable nor surveyable by non-experts. ${ }^{4}$ For example, what the Intergovernmental Panel on Climate Change (IPCC) knows about the impact of reduction of population in Japan and the simultaneous hike in oil prices on climate change is something the average citizen or political official would not understand, even if the informational basis of the knowledge were made public. It's not just that the average citizen or elected official can't be expected to have this knowledge. And it's not just that an institution like the IPCC has more resources in the way of high quality inputs and time to review those findings to acquire the knowledge. The content of the knowledge is simply not something that non-experts could work out together given time and availability of research on the subject matter. ${ }^{5}$ Moreover, even individual experts contributing to, say, the IPCC's investigations, might not grasp the information sufficiently to have knowledge of it. Often, single members just can't hold all the relevant information in their heads in the way necessary for understanding it, much less figuring out an optimal solution. The institutional procedures for integrating information across disciplines give it more powerful computational abilities than individual agents. ${ }^{6}$

Specialized institutions' knowledge is also optimal: given the available research and methods for processing data, that knowledge is the most accurate we can currently hope to have. If put to the test, the specialized institution will reliably outperform individuals and groups of non-experts in getting the correct answers on the subject matter of its expertise.

\footnotetext{
${ }^{4}$ To avoid narrowing the account I will not tie what I say going forward to a particular theory of how an institution or group can come to possess information, have beliefs, or have knowledge. I will assume for the purpose of the argument that there is nothing deeply misleading about the phenomenon of an institution having some informational output that is not thoroughly understood by any member of the institution, but which is nonetheless epistemically superior to information an individual could provide.

${ }^{5}$ It's tempting to object, here, that the latest research on collective problem-solving and decision-making undermines this claim. But see Ancell (2016) for response to this objection.

${ }^{6}$ For more on how to model such procedures where values and scientific data are both at play, see Huebner and Kukla (2014).
} 
Because the institutional knowledge is optimal and not common, a special institution is in a position of privileged epistemic standing. It has epistemic authority over non-experts because it has the best evidence and information on the subject matter of its expertise. In virtue of the specialized institution's epistemic authority, would be epistemically irrational for a non-expert to believe what's contrary to what the specialized institution says without defeaters or higher order reasons against trusting the institution. Linda Zagzebski helpfully explains that an epistemic authority gives a subject a reason to believe her because, by doing so, the subject better conforms to the epistemic reasons that apply to her (2012, pp. 89-93). A specialized institution has the authority to change what believers are rationally permitted and required to believe on the basis of what it says should and shouldn't be believed. ${ }^{7}$

Finally, specialized institutions create outputs that citizens can be required to comply with on pain of punishment. When the World Trade Organization rendered a verdict ratifying the European Union ban on trading seal products, after Canada and Nordic states had contested the ban, the output wasn't just new evidence for believing that a seal ban would effectively protect the environment without creating economic distress. It was a practically binding directive for citizens in the EU: no commercial trading of any seal products except in indigenous and Inuit communities.

This condition importantly allows us to distinguish those institutions that might merely provide information that can serve as input to shape practical policy from those actually making policy and issuing directives that license state use of coercive power. The institutions themselves will not carry out coercion; just as the members of Parliament do not themselves apply and enforce the laws they ratify but charge law enforcement agencies with this task, so too the law enforcement agencies and judiciary of a government will be charged with applying and meting out the punishments outlined by

\footnotetext{
${ }^{7}$ This way of carving up the domain of influence a specialized institution has just in virtue of its knowledge keeps us from committing what political philosophers have called the expert/boss fallacy (Estlund 2008, p. 207).
} 
specialized institutions. ${ }^{8}$ In the United States, elected officials in Congress rely on recommendations of public health experts at elite universities or think tanks when crafting laws; but those institutions aren't specialized institutions in my sense, since they are just thatrecommendations. The power to determine how that information should guide law and policy remains in the hands of the elected members of the government, and what makes the laws and policies binding on the people is that they're ratified by the elected officials. Ultimately, then, this form of governing is democratic rather than epistocratic. By contrast, in the kind of limited epistocracy I want to consider here, the very same institution that has epistemic authority - the right to be believed about what should be donealso has practical authority - the right to be obeyed. ${ }^{9}$ There isn't an intermediary body issuing practical directives that ought to be followed but that citizens would be rational in disbelieving about what ought to be done. Specialized institutions that can serve as epistocratic bodies are those whose outputs that can be turned into authoritative directives without going through a democratically elected official. I'll leave further discussion of this point to the next section.

Summing up, an organization is a specialized institution in my sense only when it (i) houses expertise that constitutes optimal, noncommon knowledge about a subject matter that isn't primarily political, (ii) has epistemic standing to be believed on a particular subject matter of practical importance, and (iii) issues practical verdicts, judgments, and policies that can bind citizens to a certain course of action backed by coercive power.

\section{Is Rule by Specialized Institutions Epistocratic?}

I want to address two concerns about this way of characterizing limited epistocracy. The first is that the system of rule I've described

\footnotetext{
${ }^{8}$ I am grateful to an anonymous reviewer for calling for clarity about the coercive powers of specialized institutions.

${ }^{9}$ I assume Hohfeld's schema of correlative rights and duties in what follows - that a duty to obey the authority correlates to a right of that authority to be obeyed - and I apply the same language to epistemic authority.
} 
isn't really epistocratic because it's democracy heavily influenced by the experts, or what political scientists call "representative bureaucracy." State elected officials turn over power to specialized bodies all the time and we don't for this reason think of the state as undemocratic. The second worry is that specialized institutions as I've described them don't exist, and so neither does my favored form of limited epistocracy.

Turning to the first concern: Suppose that there are specialized institutions. As long as they're getting their practical authority from elected officials or bodies, it seems like their rule isn't properly epistocratic. Take the European Chemicals Agency's (ECHA) regulation of products on the market as an example. The agency has de facto authority in deciding that products containing ammonium nitrate with more than $16 \%$ nitrate by weight can't be used by farmers (2006). But, the ECHA gets the de facto authority to do this from democratically elected members of the EU Parliament via the EU Commission. The ECHA doesn't enforce its regulations, either. It relies on national law enforcement to punish noncompliance. It doesn't seem like France is a limited epistocracy just because it hands over a narrow power to decide whether ammonium nitrate products can enter the market or be used to the ECHA.

It might be that when an expert body like the ECHA only has de facto, not de jure, practical authority in virtue of its special knowledge, it isn't a specialized institution in my sense. Arguably, independent agencies in the United States government fail to be specialized institutions because they aren't ruling in virtue of their expertise. Rather, their de jure authority comes from the sanction of elected officials - the President and Congress, and contingently they do happen to actually have the expertise they purport to have. Sure, the elected officials might have appointed them because of their considering the institution one of expertise, but they could have just as well appointed the think-tank owned and operated by a Congress member's family because of their connection.

Suppose we don't want to concede that the United States system of government is subject to this kind of influence by factors not having to do with expertise. Consider an organization like the US Department of Education; the policy experts that compose that 
governmental body hold their positions largely because of their knowledge. The recognition of this institution's authority currently depends on the appointment of the Secretary by the President and approval from Congress. However, perhaps its right to rule-its de jure authority - doesn't depend on democratically elected officials' approval and backing, contrary to appearances. Perhaps it depends rather on the quality of the expertise housed in it. If we wanted to describe a system of government like the United States' as a limited epistocracy, then, we would need to say that the democratic branches of government just happen to express approval of institutions housing experts, but their authority is held purely in virtue of their expertise.

This suggests a more general way of resisting the objection that there are no specialized institutions: push back on the description of the ECHA and similar cases. Although it looks like the democratic body gives the specialized institution its authority, what if the institution's authority doesn't actually depend on its being selected or appointed by elected officials? That is, the institution's dictates would be binding even if the elected officials didn't sign off on them. If a specialized institution has de jure authority in virtue of its expertise, then the state in which it operates with authority is genuinely epistocratic in this limited way. It's a happy coincidence with the democratically elected branch of the government recognizes the authority the epistocratic branch has due to its special knowledge.

In a government like that of the US, regulatory and independent agencies that house expertise like the EPA and FEMA could improve dramatically in efficacy if directors weren't appointed by the executive branch (and subject to removal by the same). Consider the recent choice of the president elect of the United States to appoint a climate-change denier as head of the EPA - arguably with the aim of scoring political points with the far right and lowering regulations on capitalistic ventures in energy. Then what the EPA can do to promote sustainability might be severely limited; unregulated carbon emissions could contribute to further climate damage and disastrous results in states bordering the ocean in a few decades. 
Or consider FEMA, the agency responsible for coordinating emergency readiness and relief response efforts. The US Federal Disaster Relief Act of 1950 eliminated the need for congressional approval and action after disasters, and in 1979 President Carter transferred over all power in disaster-related authorities to FEMA. Currently, the head of FEMA is appointed by the president, and a president or state governor has to call a state of emergency for FEMA's authority to kick in. The disastrous effects of Hurricane Katrina and problems with FEMA's operations in its wake challenged the wisdom of this arrangement. People complained that the director of FEMA appointed by President Bush, Michael Brown, had inadequate experience. They blamed him and FEMA more generally, for slow and inefficient response and the Louisiana governor and New Orleans Mayor for dragging their feet in issuing the state of emergency. If directors of agencies like FEMA or the EPA earned their positions through qualifications assessed by their epistemic communities, rather than by being appointed by the president, it's plausible that certain disasters and crises could be avoided. Imagine that the National Weather Service and FEMA merged such that when the weather service made a determination about a state of emergency, FEMA's practical authority was automatically triggered. Then we would have, in my view, a genuine limited epistocracy, where the epistocratic branch of government was being run by a specialized institution.

This leads us back to the second concern, namely, that there aren't any organizations that qualify as specialized institutions. Whether or not any institutions count as specialized institutions is of course largely an empirical matter. Are there organizations, ad hoc committees, or agencies sufficiently independent of a state's elected bodies whose political power is triggered when their areas of specialization are at issue? One plausible, actual example of a specialized institution in my sense would be the World Trade Organization. When the WTO ruled on the EU seal ban, for instance, its ruling was legitimate not because it represented the will of the people or was accepted by elected officials who represent that will. It was authoritative, it seems to me, because it has political power justified by epistocratic principles: it should have the final say 
because it's the expert body. Note, too, that the response doesn't just come down to the fact that the WHO and WTO are extragovernmental agencies. The heart of the worry is about the source of the institution's political power being democratic, not whether or not the institution is a proper part of the democratic government, so such a reply would miss the point. Rather, these organizations' power appears to be justified not by their relationship to the will of the people but something else entirely, namely, their expert knowledge.

If one doesn't find the examples above convincing, that's no reason to abandon the line of inquiry about limited epistocracy. As the Hurricane Katrina example makes vivid, if we don't currently have limited epistocracies, we may well need them in order to avert disasters and better care for citizens during emergencies and crises. With the recent rise of populism in the United States and European nations, along with the evidence that the voting population is largely misinformed or under-informed about hard and social scientific facts that bear on what policies would actually best promote citizens' welfare, limited epistocracy looks much more attractive than democracy. The effectiveness of the state in securing wellbeing would be dramatically increased by farming out decisions and implementation of policy to specialized institutions.

\section{Is Limited Epistocracy Legitimate?}

Grant for a moment that I've successfully argued that limited epistocracy is a genuinely distinct type of rule from and has more instrumental value than democracy. Whether the instrumental value of a limited epistocracy is enough to shift the argumentative burden from defenders of limited epistocracy to defenders of democracy will depend on whether there's some further moral value at stakesomething beyond health outcomes, safety, economic viability that governments owe their citizens that limited epistocracy can't deliver. In this and the following sections I'll consider potential grounds for rejecting limited epistocracy even if it would produce optimal outcomes in emergency situations on matters where politicians and ordinary citizens can’t claim competence. 
For one thing, it might fail the test of legitimacy. In fact, critics of wholesale epistocracy allege that it succumbs to this problem for "one person's having the truth does not, by itself, warrant their political authority over those who do not," (Estlund 2008, 22). For another, it's far from obvious that the only kind of value a form of rule can have is instrumental - that is, the value it has in virtue of producing the best outcomes. So if an alternative form of government did better than limited epistocracy on both counts, it would certainly be reasonable to prefer it.

To defend limited epistocracy against these charges, in this section I'll argue that limited epistocracy meets the conditions of political legitimacy because it doesn't interfere with citizens' liberty except on the basis of good reasons. However, as I'll explain in the next section, in a limited epistocracy, the reasons on the basis of which specialized institutions govern aren't surveyable or appreciable to the ordinary citizen. This seems like it exacerbates the second worry with limited epistocracy - namely, that it won't realize noninstrumental values, like political inclusion, that democratic competitors offer. I devote the remainder of the paper to addressing this final worry.

First let me say a bit about what I'm assuming legitimacy is and what motivates the quest for it. According to the standard stateof-nature stories, individual liberty is the default position; states need a compelling reason to interfere with individual liberty, to make it the case that citizens can't just do what they want but have to comply with the commands of the state. The state interferes with citizens' liberties by coercively imposing on people a certain kind of social order (Pettit 2012a, pp. 59-60). To be clear, by "interference with liberty" I don't mean merely that the state changes what citizens can do in the same way an individual or corporation does (as when a multi-million dollar fast-food chain bids on the empty storefront on the corner, demolishing the chances for a local momand-pop restaurant from being able to buy it, or when someone steps out into the street and keeps those driving from moving past freely). Instead, I mean that political authorities substantively change what we're permitted and required to do. If a state is legitimate, then a new law might create a duty to rescue, for example, and make it the 
case that when a citizen sees someone in physical distress she's required to call an ambulance or police and wait with the victim until they arrive. Having the power to reorganize and introduce new obligations into the social fabric is a huge imposition on citizens' lives. So it requires special justification. I'll follow contemporary political philosophers in calling this need to justify the coercive imposition of the social order the "burden of legitimacy" (Richardson 2002, p. 23).

Many defenders of democracy think that in order to discharge the burden of legitimacy the state has to represent the will of the people, or to acquire its power to rearrange permissions and duties by some form of consent on the part of the people. Democracy uniquely meets this condition. Other democrats make weaker claims but still tie legitimacy to the people: David Estlund, for instance, proposes an "acceptability requirement": "a necessary condition on the legitimate exercise of political power [is] that it be justifiable in terms acceptable to all qualified points of view," (Estlund 2008, p. 41).

If this is the right way to think about legitimacy, it seems to spell trouble for limited epistocracy. In a limited epistocracy, the epistocratic branch of government which doesn't even purport to be constrained by what's acceptable to non-experts. (Recall from the previous section that if the governing specialized institution depended for its authority on appointment from elected officials, it wouldn't be genuinely epistocratic and so the overall form of rule wouldn't be a limited epistocracy in my sense.) A defense of limited epistocracy on this point, then, has to begin with an explanation of how the imposition of this kind of regime could be legitimate even when the people don't offer their consent and when it doesn't give voice to their collective will.

It's initially tempting to think that democracy neatly dissolves the problem of legitimacy; for if the question "how a [person] can be both free and coerced to conform to wills which are not his own," as Rousseau puts it, then an easy answer is that the will to which a citizen of a democracy submits is, in a sense, his own. ${ }^{10}$ But contemporary democrats themselves reject this position as too naive.

10 This is Pettit's take on Rousseau's suggestion (2012, p. 65). 
The will of the majority is distinct from, and may even be at odds with, the individual's will.

The common thread in current defenses of democracy instead seems to be that democratic governments earn their legitimacy by giving reasons acceptable from all qualified perspectives of citizens for the coercion they impose. Here is Estlund on the Rawlsian liberal principle of legitimacy: "The moral idea behind this principle is that no person can legitimately be coerced to abide by legal rules and arrangements unless sufficient reasons can be given that do not violate that person's reasonable moral and philosophical convictions, true or false, right or wrong," (Estlund 2008, p. 43). And Richardson claims that the case for democracy rests on the initial premise that "governments must not act in an elementally arbitrary way but instead offer reasons for their actions," and democracy operates within this constraint by giving equal considerations to each citizen through fair procedures (2002, p. 27).

This takes us a step in the direction of defending limited epistocracy: the conditions on legitimacy described above could in principle be met by forms of government other than democracy, including limited epistocracy. The liberal principle of legitimacy dovetails with the traditional republican account of legitimacy. According to the republican theory (recently brought into the foreground by Phillip Pettit's work), the kind of freedom a state must allot to citizens is freedom from domination. Domination is understood as interference on an arbitrary basis - that is, being subject to another's arbitrary will (Pettit 1997, p. 22). Richardson helpfully contrasts interference on an arbitrary basis with interference for reasons (2002, p. 27). States discharge the burden of legitimacy, on this view, by being constrained in their interference by a principle of non-domination which requires them to interfere only on the basis of reasons (good reasons, of course). Put this way, the republican account of legitimacy looks like the other side of the coin of the liberal principle appealed to by democrats. For the notion that citizens must enjoy liberty from interference on the basis of considerations that aren't reasons - that wouldn't be acceptable from a qualified point of view - underwrites both the liberal and republican accounts of legitimacy. The point of noting this, for our 
purposes, is that if limited epistocracy interferes with liberty only on the basis of reasons that don't conflict with citizens' moral and philosophical convictions, then it can discharge the burden of legitimacy just as well as competing forms of governmentdemocracy and republics.

Specialized institutions can in fact discharge the burden of legitimacy so conceived. In fact, the impetus for putting a specialized institution in charge is precisely that they're equipped to craft policies and directives more responsive to reasons bearing on issues than is any other agency or group. Further, specialized institutions will actually make decisions on the basis of the reasons they have a handle on through their expertise. This is true because as I've conceived of them, their power isn't dependent on and constrained by parties that have orthogonal interest: lobbyists for special interest groups, congresspersons trying to get re-elected, or the executive branch pushing the party agenda. The US Environmental Protection Agency, for example, if freed from outside political influence, would make decisions on the basis of the best data available. The EPA's interference with citizens' choices won't be arbitrary, since the reasons supporting their decisions are restricted to optimal scientific evidence and social scientific data on environmental policy outcomes. Neither will these reasons conflict with the values and commitments of citizens who inhabit qualified perspectives. A limited epistocrat handles the dissent from someone convinced that climate change science is bogus is the same as the way a democrat or republican would: such a perspective isn't qualified - or, put another way, such a conviction can't be shown to be reasonable. Limited epistocracy, then, seems to be just as well positioned to meet the burden of legitimacy as democracy because it licenses specialized institutions to interfere with citizens only on the basis of good reasons, avoiding arbitrary interference.

\section{$5 \quad$ Is Limited Epistocracy Dominating?}

Limited epistocracy can discharge the burden of legitimacy because it interferes for reasons that are acceptable to all qualified perspectives. However, while those reasons are in principle acceptable, they aren't 
actually reasons that ordinary citizens and even most elected officials can be expected to appreciate; being sensitive to these reasons requires training and knowledge non-experts lack. This might generate a further worry. Because the epistocratic body discerns and acts on reasons that are inscrutable to most citizens, it threatens to dominate them - not in the way that would disqualify the institution from legitimacy, but the kind that would undermine a fundamental moral and political value: political inclusion. I want to lay out the most formidable versions of this objection to limited epistocracy in this section before responding in the next two sections.

The general argument against limited epistocracy from the value of political inclusion goes something like this: Specialized institutions impose on citizens, simultaneously, a duty to believe them and a duty to obey them. This limits citizens' permissions to form their own beliefs about political matters, deliberate for themselves and with others about what the state should do, and to formulate reasons for contesting the governing body's choices. But for citizens to participate in a way that realizes the value of political inclusion of all, they need to be able to form their own beliefs, voice their views, deliberate and formulate reasons for contesting state policy and action. Thus, limited epistocracy isn't compatible with political inclusion of all. But political inclusion has intrinsic value; in fact, its value is so great that it's better to have a state in which this value is realized than one which has maximal instrumental value. If this is right, then democracy will be preferable to limited epistocracy, even though limited epistocracy outperforms democracy when it comes to good outcomes.

What's controversial in the argument above is the premise that the joint authority of specialized institutions would keep citizens from being able to rationally deliberate, give voice to their own views, and contest the state. To lend this premise plausibility, consider first an analogy and then an example.

Imagine that the head of a science lab is in a position of epistemic and practical authority over student researchers in her lab. Years of experience lead her to think a particular student project is doomed to fail. Suppose she's right, but she finds herself unable to articulate the reasons why in terms that her students can 
understand. If she tells them the experiments they want to run aren't worthwhile, they have a pro tanto reason to believe her in virtue of her epistemic authority. If she demands that they scrap the project, they have a pro tanto reason to obey her in virtue of her practical authority. What grounds could the students have to contest the lab director's decision? It looks like the only way they could come up with a reasonable contestation is by flouting their epistemic reason to believe her. And the only way to come up with a countervailing epistemic reason or defeater is to run the experiments and get results, which would flout their practical reason to obey her. In the scientific context it doesn't matter to us that the students' hands are tied, because we don't see an obvious scientific value in giving non-experts a voice in what projects to pursue (especially when projects are costly and resources are limited). But in the political context, it does matter.

Political inclusion requires that citizens be able to rationally contest the decisions of their governments. ${ }^{11}$ But a specialized institution can give non-expert citizens a pro tanto reason to believe what it says about what should be done, or at least strong reasons to not believe the contrary of what they say; and at the same time, as practical authorities, they give citizens reasons to act in accordance with their dictates. This doesn't subject citizens to their arbitrary will, since their dictates are based on reasons. So it isn't technically a form of domination that would make the government illegitimate. However, since the reasons aren't surveyable to citizens, citizens might experience one of the harms of domination - lack of political inclusion of their voice. Like the students in the lab, non-experts won't be able to contest the political will of the limited epistocracy without violating some rational requirement, epistemic or practical. And so, though specialized institutions can meet the burden of legitimacy as articulated by the republican and liberal accounts, they still threaten to dominate citizens by stamping out their voice.

\footnotetext{
${ }^{11}$ Elizabeth Anderson argues that educated citizens can still assess scientific testimony used in public policy-making; while this may be possible in principle, in the cases we are considering, the scientific body has epistemic authority that renders it epistemically impermissible to rely on one's own assessment rather than the testimony of the specialized institution (2011).
} 
To defend limited epistocracy, I could reply that the epistemic authority of specialized institutions doesn't generate epistemic reasons strong enough to keep citizens from rationally evaluating proposals and declarations for themselves. In our science lab case, for example, the lab director certainly has a pro tanto right to be believed, but this doesn't translate to an unqualified duty for the students to believe anything she says in the subject area of her expertise. A student wouldn't be irrational to check the director's credentials, or gather and consider evidence that the director might have a kind of myopia when it comes to the particular topic of their proposed project. Higher order evidence could provide reasons against believing the director compatible with accepting her general expertise. Or disagreement within the scientific community could provide defeaters for the belief in what her director says about the project. So too, one could argue, in the political case. Citizens could gather evidence about credentials and training of members of the EPA that might discredit certain individuals; they could look to the broader community of environmental scientists and policy-makers to check the content of the EPA's claims about what they ought to believe. None of these permissions - to gather evidence or look for defeaters from disagreement - is incompatible with the EPA having epistemic authority over citizens.

Perhaps the epistemic permissions mentioned above go far enough in making room for non-experts to rationally contest the authority. If so, then limited epistocracy doesn't pose any special threat of subtle domination by undermining political inclusion. Political inclusion would be realizable in a limited epistocracy just as easily as in a democracy. That would tip the balance in favor of limited epistocracy, given its ability to outperform democracy in cases where the elected officials lack competence or make decisions that don't reflect competence because of ulterior motives.

But perhaps these epistemic permissions aren't enough to secure for citizens what they need to be included. In real life cases, non-expert citizens need to be able to make reasonable requests and demands for change, contesting the decisions of the epistocratic branch of government. If the epistemic authority of specialized institutions makes it irrational for citizens to disbelieve what they 
say ought to be done, what could be the point of their deliberating individually or with one another about what to do? Public dialogue on the issues in question would seem like nothing more than a facade covering up the fact that citizens were merely being given a Machiavellian forum to "vent" while remaining powerless. If the specialized institution is in the best position to craft an optimal proposal, then citizens would have to violate a rational requirement (ignoring pertinent information, discounting the testimony of experts, forming beliefs based on insufficient or bad evidence) to come up with reasons for complaint or an alternative proposal in their deliberations.

At this point, an example will help us see how specialized institutions' joint epistemic and practical authority could undercut citizens' ability to be politically engaged and included while complying with epistemic and practical norms. In 2014, Liberia's first line of response to the Ebola epidemic came from the Liberian Ministry of Health and Social Welfare, which created a senior strategy team with a technical expert committee. In late July, the strategy team decided that "the overall response could be further optimized and sought to implement improvements with technical support from the CDC." ${ }^{12}$ Unfortunately, despite the collaborative efforts of the technical experts in epidemiology and public health on the strategy team, Ebola continued to spread. In hindsight, researchers identify as a major impediment the cultural and religious beliefs of non-expert citizens who refused to comply with the state measures. $^{13}$

These citizens weren't in a position to rationally challenge the directives that strategy team went on to issue because they didn't have reasons to discredit the strategy team's epistemic authority; they also lacked evidence that their alternative forms of healing worked. As a result, the government and strategy team weren't compelled to listen to their dissent. If citizens preferred the use of traditional medicine and spiritual healers and continued cultural

\footnotetext{
12 Pillai et al, "Developing an Incident Management System to Support Ebola ResponseLiberia, July-August 2014" in CDC Weekly 63(41):930-933.

${ }^{13}$ Manguvo, Mafuvadze, "The Impact of Traditional Religious Practices on the Spread of Ebola in West Africa: Time for a Strategic Shift" Pan African Medical Journal 22(2015): 9.
} 
burial practices that endangered the community, even when there was ample evidence that they weren't as effective in combatting the virus, that was a problem of compliance. It seems clear that in this case, the non-expert citizens should have deferred to the medical experts who were part of the state's strategy team in forming beliefs about the virus and treatment methods. Thus the grounds they offered in contestation of the regulations, and in justifying their lack of compliance, were dismissed as unreasonable.

Not only did evidence overwhelmingly favor the modern medical treatments; but given that the problem was so urgent, it would have been a waste of resources and time for these citizens to conduct their own experiments to justify the use of their traditional medical and spiritual healing practices. So gathering further evidence wouldn't have been rational in this case. As a result, we see that the Liberian citizens were required, by practical rationality, to follow the government regulations and were required, by epistemic rationality, to believe the state about the reasons for complying with those regulations. Epistemic permission to consider higher order evidence didn't offer them room to reasonably dissent or contest the laws based on their cultural or religious values. The case above seems to drive home the point that limited epistocracy will fail to include citizens in the political process through their rational deliberation and contestation.

From the theoretical perspective, we can better appreciate the force of this challenge to limited epistocracy by looking at the determinants of political inclusion and considering why limited epistocracy would be in tension with those determinants. Philosophers characterize political inclusion as giving citizens "the right to participate in the rule of their government... making sure that all participants of the deliberative debate are actually allowed to and able to voice their views during the debate." (Beckman 2008, p. 348). ${ }^{14}$ Further, it's not enough for citizens to "feel heard"; they have to actually be heard. Their voice must be taken up as a consideration bearing on what the state should do. Social scientists and psychologists have identified mechanisms that can be weaponized

\footnotetext{
${ }^{14}$ See also Chappell (2012, p. 72). For fuller treatment see Chappell (2012, p. 72 especially) and Young (2002).
} 
against groups or individuals by making them feel feel heard without actually being heard (Trout 2013, p. 1272). In democracy, what distinguishes ersatz inclusion from genuine inclusion is the autonomy of citizens in developing their own qualified perspectives and the participation in public deliberation that results in political decisions. A citizen can't just parrot views fed to her by political campaigns, lobbyists, or mass advertising if she's to rightly call the perspective she gives voice to her own. The notion that citizens' voices are being heard can't get traction unless they're able to arrive at their considered views through reasoning, rather than being manipulated into views that will serve third parties.

The problem for limited epistocracy is that citizens rationally shouldn't develop their own perspectives on the matters where a specialized institution rules precisely because such perspectives won't be qualified. When a body of experts like the IPCC has already told citizens what they should believe about their carbon emissions and that to reduce them they have to pay a tax, it isn't rational for those citizens to spend time trying to decide what to believe, rather than deferring, or what to do, rather than obeying. Of course, citizens can make the autonomous decision to trust the specialized institutions regarding what ought to be done and why it ought to be done. The issue is that such trust is not invited, but rationally demanded. If that's right, then limited epistocracy presents a special threat of domination by imposing duties on citizens and narrowing their permissions to the point where the only reasonable option is to defer and obey. Anything short of this sort of complete trust of the authority of specialized institutions in the area of their expertise and political power can be discounted as a violation of epistemic or practical rationality. The determinants of political inclusion, then, will be off limits, normatively speaking.

The defender of limited epistocracy could resist this version of the objection by claiming that practical reasoning always involves premises about values or commitments - what G.E.M. Anscombe calls a "desirability characterization" - that lie outside of specialized institutions' expertise (1957). And that's what citizens can reason autonomously and deliberate about together, forming their own voices and making those voices heard. For example, a climate change 
denier might be epistemically irrational in rejecting the testimony of climate science experts regarding the relationship between carbon emissions from air travel and climate damage. But those experts aren't moral experts. That is, they don't have the standing to tell the climate change denier she ought to prioritize mitigating climate damage over combating other problems, like poverty and hunger. We might expect this to open up space for her to be autonomous in her practical reasoning about the state's climate policies in a limited epistocracy. She can accept the premises that air travel contributes significantly to climate change, that climate change poses a significant threat to the livelihoods of people in low-lying islands and coasts as well as future people, and that the best means of combating climate change is for the government to impose a carbon tax on air travel, and this still allows her to resist the conclusion of the practical deliberation, "pay a carbon tax for air travel." For that practical conclusion to be justified by the reasoning, combating climate change has to be characterized as wanted or desirable. And that characterization of prioritizing mitigating climate damage as desirable is what the specialized institution in a limited epistocracy can't rationally compel the citizen to accept.

I think this response is partly right, and it highlights why limited epistocracy fares better than wholesale epistocracy. In a wholesale epistocracy, the expertise claimed by governmental institutions is political and maybe even moral. The wise don't just know how to achieve goals that citizens decide on together or agree to; they also know which goals the state ought to have. Although the more frequent criticism of wholesale epistocracy in recent literature has been about the difficulty of discerning who the experts are - who has the right account of what's good for the nation and its citizensthe challenge I've been presenting in this section could easily be leveled against wholesale epistocracy. It keeps citizens from engaging in autonomous deliberation and choice by providing them with the first premises and middle terms of practical reasoning (like, "We ought to prioritize mitigating climate change" and, "The best way to mitigate climate change includes a policy that taxes carbon emissions for air travel), such that they're rationally compelled to comply with the state's directives. By contrast, in a limited epistocracy, the 
specialized institutions claim epistemic authority about a subject matter that's primarily non-political (e.g. environmental science, medicine, public health). Even if the government can fix the conclusion of their practical reasoning - what's to be done - and the middle term of it - the reasons for which it's to be done - the conclusion isn't entailed by the premises supplied by the government, so it's rationally permissible for the citizens to do what's required but believe it shouldn't be done. That may be enough to reasonably contest the state in a limited epistocracy.

What's not satisfying about this response, though, is that it condones the state issuing directives that citizens will end up rejecting because they reject a suppressed premise about value. And consequently, we can expect low rates of compliance with the specialized institutions' directives. This is what happened with the Ebola crisis in Liberia: citizens with different evaluative outlooks, who valued spiritual health and religious rituals more than bodily health, refused to comply with the laws and directives issued by the government's senior strategy team. In the United States, the Affordable Care Act, which requires Americans to have health insurance, took effect in 2010; but as of 2016, 11.9\% of Americans remain uninsured (2016). Many Americans just don't agree with the underlying assumption that caring for the basic health of citizens is the responsibility of the federal government, or that the means the government should use to provide healthcare is by forcing them into the insurance marketplace. Over 27.5 million citizens choose to pay an annual penalty rather than comply with the law.

Low rates of compliance like this threaten to seriously hamper the efficacy of a limited epistocracy. But the main advantage of limited epistocracy over democracy and other competitors is supposed to be efficacy. So the argument for limited epistocracy would be significantly weakened if, in practice, limited epistocracies were less effective in getting citizens to abide by the laws and policies generated by specialized institutions.

\section{Saving Political Inclusion}


So far, I've defend limited epistocracy against the objections that it's not truly distinct from democracy, that specialized institutions don't exist, and that specialized institutions in a limited epistocracy would fail to be legitimate. In the previous section I attempted to offer the best form of the argument that limited epistocracy will undermine the basis for citizens' political participation and inclusion. My aim in these final two sections is to propose one way to make limited epistocracy compatible with political inclusion. I'll suggest that imposing a constraint on the form of specialized institutions' directives will ensure that citizens have space to engage in the political process in a meaningful way without violating rational requirements.

If citizens of a limited epistocracy are going to experience genuine political inclusion, they're going to need to have some autonomy in their deliberation and choice. As I explained earlier, if a citizen were rationally compelled to act as a specialized institution directed her and to accept on trust what the institution says are the reasons justifying that action, then the citizen wouldn't be contributing to the process of practical reasoning and action. At best, her contribution would be the choice to trust the institutionbut when there's no rational alternative, such a contribution is hardly meaningful. It's certainly not the sort of contribution that could generate grounds for contesting the state.

The situation in a limited epistocracy isn't unlike the situation of parents trying to balance producing good outcomes for their children with providing them the opportunity autonomous choices. A parent/child analogy can help shed light on a strategy for making limited epistocracy compatible with individual autonomy in the right way.

Academic Parent: Josh is a preteen whose mother researches sleep disorders in adolescents. Josh's mother tells him he needs to be in bed by ten on school nights to get the right amount of sleep and she has the standing to demand that he try to get that amount of sleep on school nights. 
Compare Josh's situation with that of his friends. When their parents set a bedtime, they can always challenge them about whether that's in their best interest without epistemic irrationality. These kids have a chance to contest their parents' rules by questioning the grounds for the rules through their own reasoning and inquiry. Josh's friends may be epistemically irrational to disbelieve Josh's mother when she tells them when the should be going to bed; yet she doesn't have the standing to make them actually go to bed when they should. But Josh has to believe what his mother tells him and do what she tells him to do in light of what she says he should believe. One way Josh's mother might try to help him develop autonomy is to give him some options. She can say, "Okay, Josh; you can either go to bed at ten, go to bed later and take a nap when you get home from school, or stay up late and suffer the consequences." Of course, if she includes the last option for too long, of course, and Josh doesn't learn to value the health benefits of sleep for himself by suffering from sleep deprivation, then she won't be striking a balance between conferring the benefits of her knowledge on her son and allowing him to become more autonomous.

In the same way, we might think that specialized institutions in a limited epistocracy could offer citizens multiple ways of acting on the basis of the reasons that are inscrutable to them. That would provide them with space to practice rational deliberation and choice. Unlike in the Academic Parent case, though, there's a problem with specialized institutions allowing citizens to make poor choices, because the poor choices of citizens can drastically affect the lives of fellow citizens. Whereas Josh is primarily the one who will suffer the consequences if he opts to stay up late and not take naps, citizens in a limited epistocracy might keep fellow citizens from experiencing the full benefits of a limited epistocracy if they choose to not comply with the specialized institutions' policies and suffer the consequences (as when US citizens opt to pay the penalty for not getting health insurance and drive the costs of insurance up for others). Is there a way for specialized institutions to give citizens options while still producing better outcomes than democratic governments?

I think there is. To see how this can be done, we first need to recognize that an important but often overlooked feature of practical 
reasoning is that we can "throw the process into reverse." That is, we can see what action follows from commitments and beliefs we have, and without rational mistake, abandon one of those commitments because we want to avoid the conclusion. Say, for example, I'm en route to a friend's house for dinner and I form the intention to pick up flowers for her. I have a commitment- (1) bring something nice to dinner - and a relevant belief- (2) flowers are nice - that lead me to form a further commitment- (3) bring flowers to dinner. Then, I realize that the flower shop is out of the way and if I stop in to buy flowers, I'll be late. Now I think: (4) if I bring flowers, then I'll arrive late; and the natural commitment that follows is that I (6) arrive late. Instead of accepting the conclusion, though, I'm perfectly free to rethink things and do away with my commitment to (4) bring flowers to dinner. ${ }^{15}$ Notice how this is unlike theoretical reasoning. If I had reason to believe (1) today is Monday and (2) I'm going to dinner with my partner on Monday, and I reasoned from this that (3) I'm going to dinner with my partner today, I couldn't simply abandon one of the premises because I didn't want the conclusion to be true (perhaps because I also promised my friend I would meet her for dinner tonight). Philosophers observe that practical reasoning, unlike theoretical reasoning, generates requirements that are "wide in scope"- they require coherence among your synchronic beliefs and commitments, but allow you to change commitments over time.

What if the directives of specialized institutions, then, were wide in scope, providing the kind of normative openness characteristic of practical reasoning? I want to suggest that the

\footnotetext{
15 John Broome has characterized this feature in terms of the "wide scope" of rational requirements (2007). When a requirement of rationality is wide in scope, it takes the form "ought (if $p$ then $q$ )" where the ought ranges over the conditional, rather than distributing. "Ought (if $p$ then $q$ )" isn't equivalent to "if ought $p$ then ought $q$." Take $p$ to be "bring flowers to dinner" and $q$ to be "arrive late." It would be irrational of me to maintain at once an intention to bring flowers to dinner and to not arrive late. But, it is perfectly rational for me to get rid of the intention to bring flowers $(p)$, once I see that it's in conflict with my intention to arrive on time $(\sim q)$. If the requirement were narrow in scope, then once I'd formed the intention to bring flowers, I'd be bound to intend to be late since it follows from bringing flowers. Wide-scoping does away with the difficulty of making a person stuck with a premise once she's adopted it, come what may. Richardson says, "In this way, wide-scope requirements attempt to model the openness of reasoning, which can be thrown into reverse. Reasoning is thus, we might say, freely conducted," (Richardson 2012, p. 96).
} 
notion of wide-scope requirements can help us articulate a way specialized institutions can respect citizens' autonomy without capitulating to demands which are unreasonable or will render the laws and policies ineffective. Suppose the epistemic requirement to believe the experts in a specialized institution is narrow in scope. That is, the specialized institution can't just say to citizens, "believe what you will about the effectiveness of mosquito nets in preventing malaria" or "you don't have to take my word for it that this immigration policy will increase the national debt significantly." The verdicts of specialized institutions on social scientific or hard scientific facts should serve as premises in citizens' reasoning.

We can still protect citizens' autonomy by granting them the ability to choose what follows from the beliefs they form trusting specialized institutions - that is, if the institutional directives offer multiple routes for compliance. In the case of my deliberating about whether to bring flowers to dinner, I have the freedom to choose to be late but bring flowers, or to come bearing no gifts but arrive on time. Perhaps my choice will reflect what I value more- punctuality or hospitality. So too, when laws and policies provide citizens with multiple options, they can make choices that reflect their individual values and commitments.

To put it slightly more technically but more precisely, I suggest the directives of specialized institutions should create duties that take the form, "ought (if $p$, then phi) or ought (if $q$, then psi)" where $p$ and $q$ represent evaluative beliefs outside the specialized institution's area of expertise and phi and psi are courses of action. Or the duties created by the directives might be put in the negative: "ought not (if $p$, then not phi) and ought not (if q, then not psi)." Laws and policies of this form secure space for citizens to make autonomous decisions about what to do on the basis of what matters to them. This gives us the following criterion to ensure that limited epistocracy is compatible with the main determinant of political inclusion:

Conditional Form Thesis: A directive of a specialized institution adequately respects autonomy iff it is a disjunction of conditionals, " $\phi$ or $\psi$," such that citizens have a wide-scope 
obligation to $\phi$ if they have certain evaluative beliefs and to $\psi$ if they have contrary evaluative beliefs.

It seems like if the epistocratic branch of government in limited epistocracy satisfies the Conditional Form Thesis, it will be able to maximize good outcomes afforded by specialized knowledge without cutting off citizens' autonomous deliberation and choice.

\section{Refining the Conditional Form Thesis}

The Conditional Form Thesis will certainly carry limited epistocracy closer to the ideal of a state that outperforms democracy while still realizing the value of political inclusion of the citizens. Still, democrats might worry that one of the problems with wholesale epistocracy — what's called "the demographic objection" - also plagues this version of limited epistocracy. To respond to this concern I want to add a further amendment to the Conditional Form Thesis in this final section.

Estlund puts the demographic objection to epistocracy this way:

"The Demographic Objection: The educated portion of the populace may disproportionately have epistemically damaging features that countervail the admitted epistemic benefits of education," (2003).

The demographic objection need not be necessarily or conceptually true; but as long as it's contingently true here and now, and democracy can do better, it's a weighty reason against adopting epistocracy. ${ }^{16}$ The correlation between being part of the educated elite and, say, racism or sexism poses a serious threat to political inclusion.

\footnotetext{
${ }^{16}$ It's far from clear that the demographic objection does the democrat any favors. Thomas Mulligan has argued that the demographic objection proves too much, as not even democracy can escape the criticism. Mulligan cites extensive evidence from researchers like Bryan Caplan that shows the biases that undermine the epistemic value we might attach to democracy on the basis of Condorcet's theorem regarding aggregation of knowledge (2015).
} 
Plausibly, the demographic objection applies to limited epistocracy because conjectural features could be present among experts housed within specialized institutions. In many countries, to rise in the ranks of disciplines in which specialized institutions house expertise (medicine, public health, social sciences) requires costly education. A dearth of experts from underprivileged backgrounds could justify a concern that the people running specialized institutions won't be sufficiently sensitive to interests of the least well off - or worse, that they'll be biased against the underprivileged class.

Second, in fields like engineering and computer science with growing relevance to problems national governments need to solve, the workforce is overwhelmingly populated by a single demographic. In the United States, in $201351 \%$ of those employed in science and engineering were white males, as compared with $20 \%$ white women, $3 \%$ black men, $2 \%$ black women, $4 \%$ hispanic men, and $2 \%$ hispanic women. With so little representation, black and hispanic minorities as well as women could have their concerns systematically overlooked by specialized institutions in science and engineering. And yet, it stands to reason that if that happened it would be exceedingly difficult to pin down the source of the bias, as the outputs of a specialized institution depend on complex consolidation and synthesis of information that no single person could fully understand the reasons supporting them.

Third, as mounting evidence suggests that conservatism and traditional religions tend to be underrepresented in academia in the West, it would be reasonable for conservatives and religious persons to worry that specialized institutions will discriminate against them. If specialized institutions issued directives and made laws that failed to consider these points of view, they might have a legitimate worry that they wouldn't be able to live out their commitments. ${ }^{17}$

On one way of thinking about the demographic objection, the problem is not simply unequal representation of demographic groups but rather that such inequality in representation will result in

\footnotetext{
${ }^{17}$ See Shields and Dunn, Passing On the Right (Oxford: Oxford University Press, 2016).
} 
underrepresented groups not being able to live according to their deeply held values because their voices aren't heard.

The Conditional Form Thesis doesn't seem to help limited epistocracy on this front. Return to the example of the Ebola outbreak in Liberia. Imagine that the epistocratic branch of the government issues a directive like, "Either (if you value physical health and believe in the use of Western medicine, evacuate) or (if you value local religious rituals and the use of traditional medicine, then pay a fine to subsidize the cost of evacuations of others)." This fits the Conditional Form Thesis.

The obvious problem with the directive is that it threatens to marginalize certain religious and cultural groups. It imposes a serious burden on those who don't accept modern Western medicine and who are part of the religious minority, while using the financial gains from that group to lessen the burden of the majority. If some cultural or religious groups have parochial reasons to stay near to their communities during crisis rather than evacuate because of their particular values or commitments, then they incur a huge cost. What if they aren't able to pay the penalty? Neither option will be a live option, compatible with their evaluative commitments. While the reasons the experts have for issuing these two options may be nonarbitrary, the effect is to limit the liberties of some groups disproportionately. Those in the religious or cultural minority will have reason to feel disenfranchised and excluded, even if in some meager sense they retain the autonomy necessary for political inclusion.

To achieve robust political inclusion, such groups need to be guaranteed some latitude in their deliberation and decision-making that doesn't conflict with their reasonably held commitments and values. The alternatives a specialized institution provides in its directive, then, ought to be genuinely actionable and not require that people give up their reasoned fundamental commitments if we're to sidestep the demographic objection.

Conditional Form Thesis*: A directive of a specialized institution adequately respects autonomy iff it is conditional in form, generating a wide scope requirement that $\mathrm{S}$ (if $\mathrm{p}$ then $\Phi$ ) 
or (if $\mathrm{q}$ then $\psi$ ), and both $\Phi$ and $\psi$ are actions $\mathrm{S}$ can do willingly without foregoing her reasonable fundamental commitments.

On Conditional Form Thesis*, the strongest version of a directive specialized institutions are permitted to issue gives citizens real options. It should provide as many options as necessary to guarantee that minority groups with contrary evaluative outlooks or perspectives can make a choice that's consistent with their identity and commitments.

An advantage of Conditional Form Thesis* is that citizens can fairly experiment with different responses to the same information and even help to generate suggestions to the specialized institution for further options. For instance, if the US were to authorize the IPCC to set limits on citizens' annual carbon emissions, in deliberating between various options, citizens might come up with new, creative ways to offset and reduce their emissions. This kind of creative thinking would be unmotivated if citizens were just told what carbon taxes to pay and why to pay them. Groups with conflicting interests - those who rely on fossil fuels for their income, for example - won't feel automatically marginalized and so robbed of their inclusion in democratic decision-making if there are options that can really serve as the conclusion of a practical syllogism from the facts the IPCC gives citizens and the citizens' reasoned commitments and priorities. They might gather to publically deliberate about additional options for carbon-emissions offsets that suit their particular lifestyle, only furthering the value of political inclusion, rather than having their autonomous deliberation and choice stifled prematurely.

The defender of limited epistocracy can respond to the demographic objection using the Conditional Form Thesis*. Of course, she doesn't have to; if some other constraint accomplishes the same goal - providing room for citizens with varying viewpoints and backgrounds to make reasonable choices about what to do- then limited epistocracy with that constraint will come out on top.

Another way of thinking of the demographic objection is that the simple inequality of viewpoints is something distasteful, 
unpalatable. Limited epistocracy can do away with this problem more easily: the influence of a specialized institution is narrow-it only reaches as far as the bounds of its expertise. So even if a specialized institution is demographically more homogenous than the population, the effects of the homogeneity aren't sufficiently widespread to merit the kind of concern Estlund raises for general epistocracies. $^{18}$

\section{Conclusion}

Limited epistocracy as rule by specialized institutions offers citizens benefits that democracy won't be able to, since the electorate doesn't have the relevant competence in areas like technology, public health, medicine, and environmental sustainability. This puts democrats at a disadvantage. On the one hand, they can concede that they're willing to forego the kind of solutions to complex, multidimensional problems that would secure citizens' wellbeing for the sake of extremely robust political participation of all. Such a concession is counterintuitive, for when the level of public discourse about pressing issues betrays lack of understanding on the part of the electorate, I'm inclined to be less certain of the value of robust participation in decision-making. On the other hand, democrats could accept that in these situations the government ought to defer to non-elected expert bodies, and that these bodies shouldn't be subject to the check of partisan elected officials or popular referendum. But in doing so, democrats would be admitting that participation that goes beyond the kind of political inclusion a limited epistocracy can realize isn't necessary. And that's a surprising result.

I've sought to defend limited epistocracy because I think it's important to consider the normative status of the kinds of institutions we build and empower in response to complex issues like climate change, global epidemics, and public health crises. Since these institutions so seriously shape the lives of citizens by altering their permissions and duties, we're justified in wondering what makes their exercises of practical and epistemic authority legitimate, and whether they can achieve the beneficial outcomes they generate without

\footnotetext{
${ }^{18}$ I am grateful to an anonymous reviewer for pointing out this advantage of limited epistocracy as compared to general epistocracy.
} 
dominating ordinary non-experts. Chiefly, if we value political inclusion it's crucial that we make sure that these institutions don't become mechanisms for imposing biased agendas on those who aren't among the experts in those fields.

If limited epistocracy is worth pursuing, then we'll need innovative ways to resolve apparent conflicts between democratic ideals and rule by experts. I've suggested that limiting the form of directives and laws issued by specialized institutions is one way to keep the democratic value of political inclusion alive within a limited epistocracy. Defenders of democracy or republican government may come up with further values that those forms of government realize, making them desirable even if limited epistocracy produces better outcomes. The limited epistocrat can always use the argumentative strategy I've employed here: consider whether the value could be made compatible with epistocratic rule without giving up the efficacy of epistocracy. 


\section{References}

Anderson, Elizabeth. "Democracy, Public Policy, and Lay Assessments of Scientific Testimony." Episteme 8 (2011): 144-64.

Anscombe, G. E. M. Intention. 2nd ed. Cambridge, Mass: Harvard University Press, 2000.

Brennan, Jason. Against Democracy. Princeton: Princeton University Press, 2016.

Broome, John. "Wide or Narrow Scope?" Mind 116, no. 462 (2007): 359-70.

Chappell, Zsuzsanna. Deliberative Democracy. New York: Palgrave Macmillan, 2012.

Christiano, Tom. "Democracy." Stanford Encyclopedia of Philosophy, 2006. http://plato.stanford.edu/entries/democracy/.

Estlund, David M. Democratic Authority: A Philosophical Framework. 2nd ed. Princeton, NJ: Princeton Univ. Press, 2009.

European Parliament. "REACH Regulation 2016." Concerning the Registration, Evaluation, Authorization and Restriction of Chemicals, 2006. http://eur-lex.europa.eu/legalcontent/EN/TXT/PDF/?uri=CELEX:02006R190720161011\&from $=\mathrm{EN}$.

Kukla, Rebecca, Bryce Huebner, and Eric Winsberg. "Accountability and Values in Radically Collaborative Research." Studies in History and Philosophy of Science 46 (2014): 16-23.

Landemore, Helene. "Why the Many Are Smarter than the Few and Why It Matters." Journal of Public Deliberation 8, no. 1 (2012): 1-14.

Manguvo, and Mafuvadze. "The Impact of Traditional Religious Practices on the Spread of Ebola in West Africa: Time for a Strategic Shift." Pan African Medical Journal 22 (2015).

Mulligan, Thomas, "On the Compatibility of Epistocracy and Public Reason." Social Theory and Practice 41 (3, 2015):458-476.

Pettit, Philip. "Legitimacy and Justice in Republican Perspective." Current Legal Problems 65, no. 1 (January 1, 2012): 59-82.

__ Republicanism. Oxford Political Theory. Oxford : New York: Clarendon Press ; Oxford University Press, 1997.

Rehg, William. "Evaluating Complex Collaborative Expertise: The Case of Climate Change." Argumentation 25, no. 3 (2011): 385-400.

Richardson, Henry S. Democratic Autonomy. New York: Oxford University Press, 2002.

Richardson, Henry S. "Relying on Experts as We Reason Together." Kennedy Institute of Ethics Journal 22 (2012): 100-101.

Satish K. Pillai, Tolbert Nyenswah,, Edward Rouse, M. Allison Arwady, Joseph D. Forrester, Jennifer C. Hunter, Almea Matanock, Patrick Ayscue, Benjamin Monroe, Ilana J. Schafer, Luis Poblano, John Neatherlin, Joel M. Montgomery, Kevin M. De Cock, (2014) "Developing 
an Incident Management System to Support Ebola Response - Liberia, July-August 2014" in CDC Weekly 63(41): 930-933.

Shuaib, Gunnala, Musa, Mahoney, Oguntimehin, Nguku, Nyanti, Knight, Gwarzo, Idigbe, Nasidi, Vertefeuille, (2014) "Ebola Virus Disease Outbreak-Nigeria, July-September," CDC Morbidity and Mortality Weekly Report 63, 867-872.

Trout, J. D. "Democracy and Scientific Expertise: Illusions of Political and Epistemic Inclusion." Synthese 190, no. 7 (May 2013): 1267-91. doi:10.1007/s11229-012-0226-4.

Winsberg, Eric, Bryce Huebner, and Rebecca Kukla. "Accountability and Values in Radically Collaborative Research." Values and Norms in Modeling The Progress of Science 46 (June 2014): 16-23. doi:10.1016/j.shpsa.2013.11.007.

Young, Iris Marion. Inclusion and Democracy. Oxford: Oxford University Press, 2002.

Zagzebski, Linda Trinkaus. Epistemic Authority. Oxford ; New York: Oxford University Press, 2012. 